\title{
INTERNAL AND EXTERNAL EXCHANGE RATE EQUILIBRIUM IN A COINTEGRATION FRAMEWORK. AN APPLICATION TO THE SPANISH PESETA
}

Enrique Alberola and Humberto López 


\title{
INTERNAL AND EXTERNAL EXCHANGE RATE EQUILIBRIUM IN A COINTEGRATION FRAMEWORK. AN APPLICATION TO THE SPANISH PESETA
}

\author{
Enrique Alberola (*) \\ and Humberto López (**)
}

(*) Bank of Spain

(**) World Bank. 
In publishing this series the Banco de España seeks to disseminate studies of interest that will help acquaint readers better with the Spanish economy.

The analyses, opinions and findings of these papers represent the views of their authors; they are not necessarily those of the Banco de España.

The Banco de España disseminates its principal reports and economic indicators via INTERNET and INFOVÍA.PLUS at:

http://www.bde.es

ISSN: 0213-2710

ISBN: 84-7793-678-1

Depósito legal: M. 28714-1999

Imprenta del Banco de España 


\begin{abstract}
A bstract
A simple method to estimate multilateral equilibrium real exchange rates in a cointegration framework is used to compute the equilibrium real exchange rate for the peseta. The stock of foreign assets and the evolution of sectoral prices have been considered to be the fundamentals for the real exchange rate. After testing for cointegration among the three variables, we proceed to decompose the series in a permanent and a transitory component, following the method devised by Gonzalo and Granger. The permanent component of the real exchange rate corresponds to irs (time-varying) equilibrium value, and the deviations of the actual real exchange rate from this equilibrium value gives an estimation of the degree of misalignment of the real exchange rate. The results show that the equilibrium real exchange rate displays an appreciation trend and that deviations from equilibrium are sizeable. In particular, by the end of 1998 , the peseta is estimated to be moderately undervalued with respect to its equilibrium level.
\end{abstract}

Keywords: Equilibrium exchange rates, cointegration, Balassa-Samuelson, current account. JEL Classification: C32,F31,F41 



\section{Introduction}

This paper explores the determinants of the real exchange rate for Spain in the period 1975-98. Our objective is to derive an estimate for the long-run equilibrium exchange rate for the peseta, on a multilateral basis.

Real exchange rates can be affected by any shock in the economy, but the long-term or equilibrium real exchange rate will only be modified when affected by (permanent) real shocks. Two determinants will be considered in order to derive an equilibrium path for the real exchange rate. The foreign assets position and the evolution of sectoral productivities and prices.

In the literature, the concept of real exchange rate is used in diverse contexts and the different definitions are related to one or other concept of equilibrium. Actually, we will take advantage of the different concepts of real exchange rate to establish our framework of analysis. The most general definition states that the real exchange rate is the relative price of domestic relative to foreign goods, with no further distinction. In this case, the domestic (foreign) good is a basket of all domestic (foreign) goods in the consumer price index. However, in some contexts where competitiveness or external equilibrium issues are emphasised, the basket only contains a subset of goods: those which are effectively traded. Finally, in some stances, the real exchange rate is also defined as the relative sectoral prices (the ratio non-tradable/tradable goods, considered respectively as externally and internally determined). As we will show, the foreign asset position determines the equilibrium real exchange rate in terms of tradable goods and the sectoral productivities determine the equilibrium exchange rate in terms of sectoral prices. We consider two dimensions for the real exchange rate: the net of foreign assets will be considered as the fundamental for the external exchange and the sectoral prices will be related to the internal exchange rate. Finally, the overall real exchange rate can be shown to be a linear combination of the two latter definitions. This decomposition allow us to set up a very simple empirical framework for the analysis of the equilibrium real exchange rate. 
The concept of long-run or equilibrium exchange rate has been addressed from very different approaches, from the most popular concept of purchasing power parity (PPP) implying a constant equilibrium real exchange rate, to the sophisticated concepts of FEERs, DEERs, or NATREX ${ }^{1}$ which build on the concept of structural equilibrium and require prior estimation of structural models. Our framework allows us to reconcile different approaches, since it embeds several models of real exchange rate determination; in particular, the concept of external equilibrium is based on the asset market models developed by Frenkel \& Mussa (1978) and Mussa (1984), and the concept of internal equilibrium is based on the productivity differential models of Balassa (1964) and Samuelson (1964) and/or its extensions.

From an empirical point of view, cointegration techniques provide the adequate framework to uncover long-run equilibrium relations. After showing that a cointegration relationship between the real exchange rate and the fundamentals of its external and internal component exists, we will use an orthogonal decomposition of the cointegration matrix to derive the equilibrium real exchange rate. Our main findings are, first, that the Spanish peseta was severely overvalued in the EMS; second, that the ensuing devaluations in the years 1992-95 resulted in an excessive depreciation and third, that the current level is moderately undervalued, in a context of strong US dollar and sterling appreciation in the last years.

The paper is organised as follows. In section 2, the theoretical framework is presented. After decomposing the real exchange rate into an external and an internal component, we briefly present the models which determine the respective equilibrium levels. Section 3 introduces the empirical approach to computing equilibrium real exchange rates; section 4 presents the econometric methodology and section 5 summarises the results. The final section draws some conclusions, considering the implications of the results in the context of EMU.

\footnotetext{
${ }^{1}$ See Williamson (1994), for these concepts
} 


\section{Theoretical Framework}

\subsection{Real Exchange Rate Components}

We start with the most standard definition for the $(\log )$ real exchange rate $\left(q_{t}\right)$ taking as reference the consumer price index (CPI, denoted as $p$ for simplicity):

$$
q_{t}=p_{t}-\left(s_{t}+p_{t}^{*}\right)
$$

where $s_{t}$ is the (log) nominal exchange rate, defined as the price of the foreign currency in terms of the domestic currency and $p_{t}, p_{t}^{*}$ are the log of national and domestic price indices. Real exchange rate appreciations are reflected in increases of $q_{t}$.

The CPI index is composed of two different types of goods, traded and non-traded goods (superscripts $T$ and $N$ ), so that the general price index of each country is a weighted mean of each sector price index:

$$
\begin{aligned}
& p_{t}=(1-\alpha) p_{t}^{T}+\alpha p_{t}^{N} \\
& p_{t}^{*}=\left(1-\alpha^{*}\right) p_{t}^{T *}+\alpha^{*} p_{t}^{N *}
\end{aligned}
$$

where $\alpha, \alpha^{*}$ are the shares of non-tradable goods in the general index. Substituting these expressions in 1 and rearranging terms we get,

$$
q_{t}=\left[\left(p_{t}^{T}-\left(s_{t}+p_{t}^{T *}\right)\right]+\left[\alpha\left(p_{t}^{N}-p_{t}^{T}\right)-\alpha^{*}\left(p_{t}^{N *}-p_{t}^{T *}\right)\right]\right.
$$

Two different components determine the real exchange rate. First, the relative price of tradable prices at home and abroad, expressed in domestic currency determines the competitiveness of the economy and therefore influences its external position through the current account; we will refer to this term as external real exchange rate $\left(q_{t}^{X}\right)$. Second, the differential evolution of sectoral prices between countries, weighted by the corresponding share of non-tradables in consumption will be referred to as internal real exchange rate $q_{t}^{I}$ because sectoral prices influences the sectoral allocation of domestic resources for production. Then, we have: 


$$
\begin{aligned}
q_{t}^{X} & =p_{t}^{T}-\left(s+p_{t}^{T *}\right) \\
q_{t}^{I} & =\left[\alpha\left(p_{t}^{N}-p_{t}^{T}\right)-\alpha^{*}\left(p_{t}^{N_{*}}-p_{t}^{T *}\right)\right]
\end{aligned}
$$

Finally, we define the equilibrium real exchange rate $\left(\overline{\boldsymbol{q}}_{t}\right)$ as the one in which both the internal and external balance is achieved, that is, it will be attained when both $q_{t}^{X}$ and $q_{t}^{I}$ are in equilibrium, indicated by bars ${ }^{2}$ :

$$
\bar{q}_{t}=\bar{q}_{t}^{X}+\bar{q}_{t}^{I}
$$

\subsection{The external equilibrium real exchange rate}

Portfolio models of real exchange rate determination (Branson (1978), Mussa (1984)) focus on the idea of balance of payments equilibrium. Excess saving over investment is reflected in a current account surplus, that is, an accumulation of net foreign assets $\left(N F A_{t}\right)$. The current account balance $\left(C A_{t}\right)$ consists of the trade balance $\left(X N_{t}\right)$ and the interest payments on the stock of net foreign assets:

$$
C A_{\mathrm{t}}=X N_{\mathrm{t}}+i_{\mathrm{t}} N F A_{\mathrm{t}}
$$

where $i_{t}$ is average yield on the stock of foreign assets. A positive stock of net foreign assets $\left(N F A_{t}>0\right)$ reflects a creditor position for the country. The external real exchange rate affects the trade balance, since its appreciation worsens the competitiveness of domestic products, creating a trade balance deficit, when the Marshall-Lerner condition of demand and supply elasticities holds. Therefore, we can rewrite the current account balance as a negative function of $q_{t}^{X}$ :

$$
C A_{t}=-\gamma q_{t}^{X}+i_{t} N F A_{t}
$$

\footnotetext{
${ }^{2}$ The concept of internal balance is quite loose, and it is used for expositional convenience, in order to relate it to the internal exchange rate. We refer to internal balance as a steady state situation in terms of sectoral production
} 
Following Mussa (1984), the current account balance reflects the adjustment of the net assets to its equilibrium level $\overline{N F A}$; thus, a current account surplus indicates a net foreign asset position below the equilibrium level:

$$
C A_{t}=\eta\left[\overline{N F A}_{t}-N F A_{t}\right]
$$

From these expressions it follows that:

$$
q_{t}^{X}=\frac{\eta}{\gamma}\left[\overline{N F A_{t}}-N F A_{t}\right]+\frac{\imath}{\gamma} N F A_{t}
$$

In steady state, $\overline{N F A_{t}}=N F A_{t}$ and the external exchange rate reaches its equilibrium level:

$$
\bar{q}^{X}=\frac{i_{t}}{\gamma} \overline{N F A}
$$

Note from (7) that in equilibrium the current account balance is zero. This implies that the equilibrium external exchange rate is such as to generate a trade balance surplus equal to the flow of interest payments related to the equilibrium foreign asset position. Consequently, (10) reflects the fact that an increase in the stock of foreign assets implies a higher equilibrium current account deficit, requiring an exchange rate appreciation.

\subsection{The internal equilibrium real exchange rate}

The different behaviour of sectoral relative prices between countries determines the evolution of the internal real exchange rate; in turn, sectoral relative prices are related to the evolution of sectoral productivity. We can illustrate the productivity hypothesis in a simple model with two production factors, labour $(L)$ and capital $(K)$ which are fully employed in the production of tradables and non-tradables. Output in each sector is determined by a Cobb-Douglas production technology:

$$
\begin{aligned}
Y_{t}^{T} & =A^{T}\left(L_{t}^{T}\right)^{\theta}\left(K_{t}^{T}\right)^{1-\theta} \\
Y_{t}^{N} & =A^{N}\left(L_{t}^{N}\right)^{\delta}\left(K_{t}^{N}\right)^{1-\delta}
\end{aligned}
$$


$\theta$ and $\delta$ represent the labour intensity of production in each sector. Labour is assumed to be perfectly mobile between sectors, implying nominal wage equalization, $W^{T}=W^{N}=W$. Finally, labour is paid the value of its marginal product $\partial Y^{i} / \partial L^{i}=W^{i} / P^{i}, i=N, T$. Under Cobb-Douglas technology it is easy to show that the ratio of marginal productivities is proportional to the ratio of average productivities:

$$
\frac{\partial Y^{T} / \partial L^{T}}{\partial Y^{N} / \partial L^{N}}=\frac{\theta Y^{T} / L^{T}}{\delta Y^{N} / L^{N}}
$$

It immediately follows from here that the sectoral price differential is equal to the level of sectoral productivity differentials, plus a constant term, represented by relative labour intensity. Expressing this result in logs, where $y_{t}^{i}$ is the log of average productivity, we obtain:

$$
p_{\mathrm{t}}^{N}-p_{t}^{T}=\log (\theta / \delta)+\left[y_{\imath}^{T}-y_{\mathrm{t}}^{N}\right]
$$

This result implies that higher productivity levels in the tradable sector result in higher relative prices for non tradables. Going back to the expression for the internal real exchange rate, and assuming that relative labour intensity is equal in both countries, we observe that the level of the internal real exchange rate will be given by sectoral productivity differentials between countries.

$$
q_{\mathrm{t}}^{I}=\left[\alpha\left(p_{\mathrm{t}}^{N}-p_{\mathrm{t}}^{T}\right)-\alpha^{*}\left(p_{\mathrm{t}}^{N *}-p_{\mathrm{t}}^{T *}\right)\right]=\alpha\left(y_{\mathrm{t}}^{T}-y_{\mathrm{t}}^{N}\right)-\alpha^{*}\left(y_{\mathrm{t}}^{T *}-y_{\mathrm{t}}^{N *}\right)
$$

Productivity differentials may arise from different sources. The original argument was put forward by Balassa (1964) and Samuelson (1964), who pointed out that economic growth was associated with an increase in the relative price of non-tradables. The reason is that productivity gains tend to concentrate in the tradable sector, because it is more capital intensive and technological progress is usually embedded in new capital, reducing the price of tradables. Other authors as Bergstrand (1991) have emphasised that demand factors may be behind sectoral productivity and price differentials. Since demand for services and, more arguably, public expenditure increase more than proportionally with income, v.g. their income elasticity is higher than one, inflation will tend to be higher in these 
sectors. Finally, productivity growth may also be the result of rigidities in market and labour products (de Gregorio et al. (1994)). Excessive wage pressures in the tradable sector may lead to employment adjustments to maintain competitiveness; on the contrary, in the non-tradable sector, which is covered from competition, employers may admit these wage pressures because they can be passed onto prices. As a result higher productivity growth and lower inflation in the tradable sector results as a consequence of wage pressures plus market rigidities.

In practice, it is far from simple to identify the different factors determining $q_{t}^{I}$, and we will not pursue this identification in this paper ${ }^{3}$. Since any of the above explanations may potentially drive the long-run behaviour of the internal real exchange rate, they rather serve as a warning for interpretation of the results below. In any case, it is a well-established fact that, in the long run, sectoral productivity differentials lead to sectoral inflation differentials

In what follows, we just need to note that the internal exchange rate is a function of the differential sectoral price levels between countries, as stated in the previous equation and that there may be transitory deviations of $q_{t}^{I}$ from its equilibrium level $\bar{q}_{I}$, which reflect an adjustment process in sectoral reallocation. Assuming without loss of generality that $\alpha=\alpha^{*}$, and denoting $P^{N T}=\left(p^{N}-p^{T}\right)-\left(p^{N *}-p^{T *}\right)$, we have:

$$
q_{t}^{I}-\bar{q}_{t}^{I}=\alpha\left[P_{t}^{N T}-{\overline{P^{N T}}}_{t}\right]
$$

\section{The empirical model}

\subsection{Equilibrium and cointegration}

Our theoretical digression has emphasised two main determinants of the real exchange rate $q$ in the long-run: the stock of net foreign assets $N F A$ and the relative sectoral prices

\footnotetext{
${ }^{3}$ See de Gregorio et al. (1994), for further discussion

${ }^{4}$ See Alberola and Tyrväinen (1998) or Canzoneri et al. (1998)
} 
between countries $P^{N T}$. Therefore, the empirical model to estimate is:

$$
\bar{q}_{\imath}=\beta_{0}+\beta_{1}{\overline{N F A_{t}}}_{+}+\beta_{2}{\overline{P^{N T}}}_{t}
$$

From (10) and (15), note that $\beta_{1}=i / \gamma>0$ and $\beta_{2}=\alpha>0$.

There are two difficulties to tackle this empirical problem in a standard estimation framework. The first is that OLS estimation of the series may yield spurious results if the series are non-stationary. Second, we can only observe the actual values of $N F A_{t}$ and $P_{t}^{N T}$ instead of their equilibrium values. Both considerations require to approach the issue in a cointegration framework. Let us start from the equilibrium notion for the real exchange rate $(\bar{q})$ derived from the theory of relative purchasing power parity (PPP), that is, a constant equilibrium real exchange rate.

$$
\bar{q}_{t}=\mu \text {. }
$$

Obviously, in practice it is not to expected that the real exchange rate is equal to its equilibrium value at every time period. The real exchange rate $\left(q_{t}\right)$ would be given by the following empirical model

$$
q_{t}=\mu+v_{t}
$$

where the element $v_{t}$ captures all the stochastic properties of the real exchange rate at time $t$. One would expect, on average, the real exchange rate to be equal to its equilibrium value $\mu$, that is,

$$
E\left(q_{\mathrm{t}}\right)=\mu,
$$

where $E($.$) is the expectations operator. Secondly, one would expect that there is a bounded$ limit to the deviations of $q_{t}$ from $\mu$, that is,

$$
\operatorname{var}\left(q_{\imath}\right)=\sigma^{2}<\infty
$$

This condition also ensures that when $q_{t}$ at a given period is far from its equilibrium value $\mu$ there will be a tendency for the $q_{t}$ to approach $\mu$ in the next period. 
We notice here that if $v_{t}$ follows a stationary process, $\mathrm{I}(0)$ in short, then it will satisfy conditions (19) and (20). As explained above, when those conditions are met, it makes sense to consider $\mu$ as the equilibrium value of $q$.

However, if $v_{t}$ is better described by the following process

$$
v_{t}=v_{t-1}+\eta_{t}
$$

where for simplicity $\eta_{t}$ is white noise with zero mean and variance $\sigma_{\eta}^{2}$, then, it is clear that although

$$
E\left(q_{t}\right)=\mu
$$

it is also the case that

$$
\operatorname{var}\left(q_{t}\right)=t \sigma_{\eta}^{2}
$$

From (23) it follows that as $t$ increases the variance of $q_{t}$ increases without bound, which in turn implies that $q_{t}$ may drift away from $\mu$ without bound. In other words, as time goes on any value of $q_{t}$ would be feasible, and therefore, there is no room to talk about equilibrium.

Variables that are not stationary in levels but are stationary in first differences are known as integrated of order $1, \mathrm{I}(1)$ in short. They have the characteristic of not returning to an equilibrium or mean value. Therefore, the starting point is to test whether $q$ is better described by an $I(0)$ process or by an $I(1)$ process. Note that this is also a test on PPP in the real exchange real exchange rate, which assumes a constant value $(\mu)$ for $\overline{\mathbf{q}}$.

As explained later we find that there is little evidence to reject the hypothesis that $q$ series are well represented by an I(1) process, thus pointing towards a failure of PPP. Clearly, this claim does not imply that there is not an equilibrium value for the real exchange rate, but instead that this equilibrium may be time varying.

Let us now return to our empirical problem. We could simply estimate

$$
q_{t}=\beta_{1} N F A_{t}+\beta_{2} T N T_{t}+u_{t}
$$


From the digression above, if $u_{t}$ is $\mathrm{I}(0)$ then the $q_{t}$ would fluctuate around $\beta_{1} N F A_{t}+$ $\beta_{2} T N T_{\mathrm{t}}$, and we would say that $q, N F A$ and $P^{N T}$ are cointegrated with cointegration vector $\left[1-\beta_{1}-\beta_{2}\right]$. In -this case, we could accept as a sensible hypothesis that the equilibrium exchange rate is determined by $N F A$ and $P^{N T}$. If, on the contrary, $u_{t}$ is I(1) then $q$ might shift apart without bound from the linear combination given by $N F A$ and $P^{N T}$. In such a case, no long-run relationship exists among the variables, and our model would be rejected. The second step, if cointegration is not rejected, concerns the empirical

estimation of $\bar{q}$. If we compute it as the estimate $\hat{q}_{t}$ :

$$
\widehat{q}_{t}=\beta_{1} N F A_{t}+\beta_{2} P_{t}^{N T}
$$

we would take the observed values of both $N F A$ and $P^{N T}$ as the respective equilibrium values $\overline{N F A}, \overline{P^{N T}}$, which is not very appealing from an empirical point of view. Indeed, both variables are expected to diverge transitorily from their long-run values, so that

$$
\begin{array}{r}
N F A_{t}={\overline{N F A_{t}}}+\widetilde{N F} A_{t}, \\
P^{N T}={\overline{P^{N T}}}_{t}+\widetilde{P^{N} T} t
\end{array}
$$

In these expressions $\widetilde{N F} A_{t}$ and $\widetilde{P^{N T}}$ trepresent the transitory component of the respective variables and, consequently they would follow $I(0)$ processes. Therefore, what is actually estimated is:

$$
\begin{aligned}
\widehat{q}_{t} & =\beta_{1} N F A_{t}+\beta_{2} P_{t}^{N T} \\
& =\beta_{\imath} \overline{N F A_{t}}+\beta_{2} \overline{P^{N T}}+\beta_{1} \widetilde{N F} A_{t}+\beta_{2} \widetilde{P^{N T}} t
\end{aligned}
$$

Therefore, the estimated real exchange rate $\widehat{q}_{t}$ can also be decomposed into two components. A permanent component $\bar{q}_{t}$, which would indeed be the estimate of the equilibrium real exchange rate we are looking for, and the transitory component denoted by $\bar{q}_{t}$ :

$$
\begin{aligned}
& \bar{q}_{t}=\beta_{1} \widetilde{N F} A_{t}+\beta_{2} \widetilde{P^{N T}}{ }_{t} \\
& \bar{q}_{t}=\beta_{1} \overline{N F A}_{t}+\beta_{2} \overline{P^{N T}} \bar{t}_{t}
\end{aligned}
$$


Below we will have to take into account this point in order to compute the estimates of the equilibrium real exchange rate ${ }^{5}$.

\section{Estimation and orthogonal decomposition}

In this section we review the econometric methodology used for the identification and estimation of the cointegration vectors. Among the different methods to infer the presence of cointegration we will follow Johansen's approach. There are three main reasons for this choice: firstly Gonzalo (1994) shows that Johansen's tests perform better than other approaches under various specifications errors. Secondly, Johansen's approach is able to incorporate the entire cointegration issue into the familiar VAR representation without restrictions on the exogeneity characteristics of the variables. Finally, the procedure provides simultaneously test statistics (the $\lambda$-max and Trace tests) to infer the number of cointegrating relationships and estimates of the cointegration vectors. The main difference between the $\lambda$-max and the Trace tests is that the former tests for the existence of $r$ cointegration vectors against the alternative $r+1$, whereas the latter tests against the alternative of more than $r$ cointegration vectors.

It is also important to notice here that the Johansen method does not impose any restriction on the order of integration of the series in the vector under analysis, in the sense that one could include $\mathrm{I}(1)$ and $\mathrm{I}(0)$ series in such vector. If for example, in the $N \times 1$ vector $x_{t}$ there is a series which is $\mathrm{I}(0)$, then at the very least one should find a trivial cointegration vector (a vector of zeroes with 1 in the position of the $\mathrm{I}(0)$ series). It is for this reason that it is advisable to test for stationarity within the Johansen framework after finding a cointegration restriction in any set of variables. Otherwise, there is the danger of interpreting the stationarity of a variable as a cointegration vector (i.e. as the existence of

\footnotetext{
${ }^{5}$ While the transitory component of the sectoral relative prices, $\widetilde{P_{t}^{N T}}$ is just the deviation of $P_{t}^{N T}$ from its equilibrium level $\overline{P_{i}^{N T}}$, from 9 and 10 , we note that $\widetilde{N F A}=\frac{\eta-i}{i}\left[\overline{N F} \overline{A_{t}}-N F A_{t}\right]$
} 
an economic long-run equilibrium). In particular, if the PPP holds, then one should find a trivial cointegration vector where the element corresponding to the real exchange rate is 1 , and the remaining elements are 0 .

The empirical framework to test for cointegration we define $x_{t}$, a $N \times 1$ row-vector made up by our three variables: $x_{t}=\left[q N F A P^{N T}\right]_{\ell}$. This vector admits the following representation $\operatorname{VAR}(p)$ representation:

$$
\Delta x_{t}=\Delta D_{1} x_{t-1}+\ldots+\Delta D_{p-1} x_{t-p+1}+\Pi x_{t-p}+e_{t},
$$

where $e_{t}$ is a vector white noise process with zero mean and variance $\Sigma$. In our case, $N=3$, the number of variables in estimation. There are three possibilities to consider depending on the rank of $\Pi$. First, $\Pi$ could be full rank, in which case, given that $e_{t}$ is a white noise process, $x_{t}$ should be stationary. In such a case, each of the three variables in $x_{t}$ would fluctuate around their mean values and for the purposes of this paper, we would not reject the PPP hypothesis.

Second, $\Pi$ could have rank zero and (29) would reduce to a standard VAR in differences. In such a case, all the variables would be I(1) (a rejection of PPP), there would not be any relationship linking the long-run movements of the variables in $x_{t}$ and therefore. there would be no room to talk about equilibrium.

Finally, $\Pi$ could be of intermediate rank $r(0<r<N)$ in which case there would be $r$ cointegration vectors. In this case $\Pi$ can be written as the product of two rectangular matrices $\alpha$ and $\beta$ or order $N \times r$ such that $\Pi=\alpha \beta^{\prime}$. Observe that in this case $\beta^{\prime} x_{t}$ will be stationary given the $e_{t}$ is a white noise process. Therefore. one could define the $r$ columns of $\beta$ to be the cointegrating vectors, that is the linear combination of $x_{t}$ that are stationary. and $\alpha$ to be the loading matrix, the matrix which describes how important each of those $r$ vectors are to the dynamics.

The second theoretical issue in this section refers to the estimation of the time varying 
equilibrium real exchange rate. As noted in the previous section, using the cointegration vector and the observed values of the explanatory variables may lead to misleading results since the estimate is likely to differ from the actual value $\bar{q}$ due to the presence of transitory components in both $N F A$ and $P^{N T}$. The situation studied here is analogous to the decomposition of the series into permanent and transitory components. The permanent components would capture the long-run behavior of the system, whereas the transitory components would capture the temporary deviations of the observed variables from the long-run or fundamental values.

To be more specific, consider again the $N \times 1$ vector $x_{t}$ and assume that the variables in $x_{t}$ are cointegrated with $r$ cointegration vectors. Then, as shown in Stock and Watson (1988), $x_{t}$ admits the following representation:

$$
x_{t}=A f_{t}+c_{t}
$$

where $A$ is a $N \times N-r$ matrix, $f_{t}$ is a $N-r \times 1$ vector which captures the permanent components, and $c_{t}$ is a $N \times 1$ vector which captures the transitory or desequilibium components. Clearly the reverse is also true: if $x_{t}$ admits a representation like (30) then the variables in $x_{t}$ are cointegrated with $r$ cointegration vectors.

Notice that pre-multiplying (30) by $i_{j}$ where $i_{j}$ is $N \times 1$ vector of zeroes with 1 in the $j$ element one can isolate the permanent and the transitory component of variable $j$.

In the model presented in Section $2 N=3, r=1$ and hence $f_{2} 2 \times 1$. The natural question that now arises is how estimate $A$ and $f_{t}$ (which in general is unobserved and is the driving force of the variables). Unfortunately, there is not a unique decomposition between permanent and transitory components (see Maravall (1993) for the theoretical issues involved in the identification of permanent and transitory components. Also see, among others, Quah (1992), Kasa (1992) and Gonzalo and Granger (1995) for different decompositions). Notice that since different decompositions rely on different econometric restrictions the results are 
likely to differ among them.

Here we follow Gonzalo and Granger (1995). The basic identifying restrictions of their decomposition are that the transitory components do not Granger-cause the permanent components in the long run and that the permanent components are a linear combination of contemporaneous observable variables. In other words, the first restriction implies that a change in the transitory component today, will not affect the fundamental or long-run values of the variables. The second restriction makes the permanent component observable and assumes that the contemporaneous observations contain all the necessary information to extract the permanent component.

From an econometric point of view, given the matrices of loading factors $\alpha$ and of cointegrating vectors $\beta$, such that $\alpha \beta^{\prime}=\Pi$, one can always define the orthogonal complements $\alpha_{\perp}$ and $\beta_{\perp}$ as the eigenvectors associated with the unit eigenvalues of the matrices $\left(I-\alpha\left(\alpha^{\prime} \alpha\right)^{-1} \alpha^{\prime}\right)$ and $\left(I-\beta\left(\beta^{\prime} \beta\right)^{-1} \beta^{\prime}\right)$ respectively. Observe that $\alpha_{\perp}^{\prime} \alpha=0$ and $\beta_{\perp}^{\prime} \beta=0$. With this notation it is possible to write

$$
x_{t}=\beta_{\perp}\left(\alpha_{\perp}^{\prime} \beta_{\perp}\right)^{-1} \alpha_{\perp} x_{t}+\alpha\left(\beta^{\prime} \alpha\right)^{-1} \beta^{\prime} x_{t},
$$

where the permanent and transitory components are captured by the terms $\beta_{\perp}\left(\alpha_{\perp}^{\prime} \beta_{\perp}\right)^{-1} \alpha_{\perp} x_{t}$ and $\alpha\left(\beta^{\prime} \alpha\right)^{-1} \beta^{\prime} x_{t}$, respectively. Gonzalo and Granger show that the transitory components defined in this way will not have any effect on the long-run value of the variables captured by the permanent components.

In our model these permanent components are associated to the equilibrium values of the variables, and the transitory component to the deviations from equilibrium, that is:

$$
\begin{gathered}
{\left[\begin{array}{lll}
\bar{q} & \overline{N F A} & \overline{P^{N T}}
\end{array}\right]_{t}=\left(\beta_{\perp}\left(\alpha_{\perp}^{\prime} \beta_{\perp}\right)^{-1} \alpha_{\perp}\left[\begin{array}{lll}
q & N F A & P^{N T}
\end{array}\right]_{t}\right.} \\
{\left[\begin{array}{llll}
\tilde{q} & \widetilde{N F A} & \widetilde{P^{N T}}
\end{array}\right]_{t}=\alpha\left(\beta^{\prime} \alpha\right)^{-1} \beta^{\prime}\left[\begin{array}{llll}
q & N F A & P^{N T}
\end{array}\right]_{t}}
\end{gathered}
$$




\section{Empirical Analysis}

In this section we estimate the equilibrium real exchange rates for Spain for the period 1975-1998, using quarterly data. Next, we describe the construction of the series of interest and then we present our results.

\subsection{The Data}

Our model considers three variables: the real exchange rate $q_{t}$, the stock of net foreign assets $N F A_{t}$ and the relative sectoral prices $P_{t}^{N T}$. It is important to note that the proposed model can only be tested in a multicountry context, since the data on the external position are always defined with respect to the rest of the world.

Therefore, for the real exchange rate, $q_{t}$, we use a CPI-based index of the real effective exchange rate, such as it is constructed by the Bank of Spain. It is important to note that in the construction of the series, the weight of each currency $\delta_{i},(i=$ trading partners $)$ in the computation of the peseta real exchange rate depends on the share of trade of the corresponding country. Following common practice, we use the natural logarithm of the series.

The construction of the relative sectoral prices $P^{N T}$ is based on a comparative index of the relative price of nontradable versus tradable goods, devised by Faruqee (1995). Specifically, this comparative index consists of the domestic ratio of the consumer price index $(C P I)$ to the wholesale price index (WPI) relative to the corresponding ratio of the home country's trading partners. Since the $C P I$ contains a large share of non-tradables (mainly services), in contrast to the wholesale index, which is made up mainly of tradables, the ratio of $C P I$ to $W P I$ is an increasing function of the relative price of nontradable goods. This ratio has to be consider relative to the rest of countries, whose weights are given by $\delta_{i}$. Thus, the $P^{N T}$ series was constructed as follows:

$$
P_{t}^{N T}=\frac{\left(C P I_{t} / W P I_{t}\right)}{\Pi_{i}\left(C P I_{i} t / W P I_{i t}\right)^{\delta_{i t}}}
$$


and we use the natural logarithm of $P_{t}^{N T}$ in the estimation process.

Finally, computation of the stock of Net Foreign Assets $\left(N F A_{t}\right)$ requires the computation of the initial stock. The change in the net foreign asset position for each country is obtained by adding up the current account balances $\left(C A_{t}\right)$. However, to obtain the stock of $N F A$ at a given time period we need a value of initial assets, which is not available. Note however that net foreign income at time $t\left(N I_{t}\right)$ is given by

$$
N I_{t}=i_{t} N F A_{t}
$$

where $i_{t}$ is the average effective interest rate paid or received on $N F A$ at time $t$. The value for $N I(1975: 1)$ is known, and Dolado and Viñals (1992) estimate a value for $i_{1975}$ equal to $10.2 \%$. Applying the formula, the stock of initial assets can be estimated.

Figures 1 to 3 plot the real effective exchange rate, the relative price on non-tradable goods and the ratio of the stock of net foreign assets to GDP which is the dataset for our estimation.

\subsection{Results}

Table 1 reports the results of the Johansen tests for the sample under analysis as well as the results of the stationarity tests. Stationarity of $q_{t}$ would imply that the PPP holds, but as we observe all the estimators exceed the critical values, that is, none of the variable is rejected to be $I(1)$, implying that cointegration is potentially possible among them.

Next, the table reports the cointegration results using 2 lags in the VAR. The number of lags has been chosen according to the Hannan and Quinn information criterion. The results show evidence of the presence of one and only one cointegration vector at the $10 \%$ level. The coeffcients of the cointegration vector, $[1-.31-.42]$ have the right sign and the magnitudes are sensible: a $10 \%$ change in the long run value of the net foreign assets stock $\overline{N F A}_{t}$ appreciates $\bar{q}_{t}$ by around $3 \%$; an equal change in the long-run relative price of non-tradable goods $\overline{P^{N T}}$ leads to a $4.2 /$ rate. 
The estimation of the $\bar{q}_{t}$, follows the Granger and Gonzalo decomposition as defined in expression 32 . Figure 4 plots the estimated equilibrium real exchange rate $\left(\bar{q}_{t}\right)$ and the actual observed value $\left(q_{t}\right)$. Figure 5 plots the deviations from the equilibrium exchange rate $\tilde{q}_{t}$, that is, the transitory component, as well as the 95 percent confidence bands. ${ }^{6}$.

Inspection of these figures suggests that the equilibrium real exchange $\bar{q}_{t}$ displays a slight upward trend and that the observed series tracks this trend although the transitory deviations from the equilibrium are important. For example in the late 1970s we find evidence of an overvaluation of the Spanish Peseta by around 12 percent. The Spanish Peseta then depreciates in the early 1980s to reach equilibrium in 1982 and after further depreciation it is undervalued by around 10 percent in 1983 . The Peseta remains below equilibrium for around 5 years and in the late 1980s, just before entering the EMS, it starts to appreciate. The EMS period is characterised by a continuous and severe overvaluation of the peseta, due to the strenght of the peseta in the system, the persistence of inflation differentials and the weakness of the dollar.

The peak of overvaluation (around 14\%) was reached just before the crises of the EMS. The ensuing peseta devaluations placed the currency well below its equilibrium level and then started to adjust to equilibrium again, but the last devaluation of the peseta in the EMS (1995:1) shifted it again far from equilibrium. Thereafter, the trajectories of the equilibrium and actual exchange rates have diverged and, according to our exercise the peseta is undervalued by a $5.8 \%$ at the end of 1998 . If the standard error bands are considered this gives a range of 4.9-6.7\% undervaluation. This undervaluation can be partly explained by the strong performance of the dollar and pound in the last years. Indoed, the peseta quickly recovered the levels prior to the 1995 devaluation against the EMS currencies, but instead the dollar and the pound have surged during this time. ${ }^{7}$

\footnotetext{
${ }^{6}$ See the appendix for details on the computation of these bands

${ }^{7}$ From $1995: 1$ to $1998: 1$ the pound and the dollar have appreciated $22 \%$ and $16 \%$ respectively against the peseta
} 
Finally, regarding the speed of adjustment, the factor loading of the cointegration vector is estimated to be -.15 (s.e. .06) implying a half-life (the expected time to move half way towards the equilibrium) of 4.16 quarters, that is, more than one year. Similarly, the period to move from a disequilibrium point to within 10 percent of the equilibrium would be 13.8 (around four years and a half) suggesting that once there is a disequilibrium a significant amount of time may be needed to reach the equilibrium again.

\section{Conclusions}

In this paper, we have devised a simple method to estimate multilateral equilibrium real exchange rates in a cointegration framework. The stock of foreign assets and the evolution of sectoral prices have been considered as the fundamentals for the real exchange rate. After testing for cointegration among the three variables, we have proceeded to decompose the series into a permanent and a transitory component, following the method devised by Gonzalo and Granger. The permanent component of the real exchange rate corresponds to its (time-varying) equilibrium value, and the deviations of the actual real exchange rate from this equilibrium value, once standard error bands are computed, provide an estimation of the degree of misalignment of the real exchange rate.

This methodology has been applied to the estimation of the peseta equilibrium real exchange rate. The results show that the equilibrium real exchange rate tends to appreciate and that deviations from equilibrium are sizeable. In particular, the EMS period was characterised by a severe overvaluation of the peseta, and the following devaluations have shifted the exchange rate somewhat beyond its equlibrium value, leading to a moderate undervaluation by the end of the sample, which can be mostly explained by the strong behaviour of the dollar and the pound.

The birth of EMU and the locking of nominal exchange rates with in the euro-area area arise the question of the possible misalignment of the peseta with the EMU partners. However, the multilateral frawework in which the analysis is carried out prevents us from 
doing any statement on this issue. In our context, the right way to address this relevant question would be to the estimate multilateral equilibrium exchange rates of every currency, so that the overall computation is consistent and from there to compute relevant bilateral rates, among them, the equilibrium euro-peseta rate. We intend pursue this line of research in future work.

\section{References}

Alberola, E., T.Tyrväinen (1998) "Is There Scope for Inflation Differentials in EMU," Bank of Spain WP n. 9823.

Balassa, B. (1964) "The purchasing power parity doctrine: A reappraisal". The Journal of Political Economy, 72 .

Bergstrand, J.H. (1991) "Structural Determinants of Real Exchange Rates and National Price Levels: Some Empirical Evidence”, The American Economic Review, vol. 81, no 1 .

Canzoneri, M. B., B. Diba and G. Eudey (1998) , "Trends in the European Productivity and Real Exchange Rates: implications for the Mastricht convergence criteria and for inflation targets after EMU", forthcoming in Journal of International Economics.

De Gregorio, J., A. Giovannini and H.C. Wolf (1994) , "International Evidence on Tradables and Nontradables Inflation"; IMF Working Paper WP/94/33.

Farugee, H. (1995), "Long-Run Determinants of the Real Exchange Rate: A StockFlow Perspective," IMF Staff Papers, March.

Frenkel, J. and M. Mussa (1985), "Asset Markets, Exchange Rates, and the Balance of Payments, ${ }^{n}$ Handbook of International Economics, Chapter 14. 
Gonzalo, J. (1994), "Comparison of five alternative methods of estimating long-run equilibrium relations." Journal of Econometrics, 60, 203-234.

Gonzalo, J. and C. Granger (1995), "Estimation of Common Long-Memory Components in Cointegrated Systems," Journal of Business and Economic Statistics, 13, 27-35.

Johansen S. (1988), "Statistical Analysis of Cointegration V'ectors," Journal of Economics Dynamics and Control, 12, 231-54.

Lutkepohl H. (1993), Introduction to Multiple Time Series Analysis, Springer-Verlag, Heilderberg.

Maravall, A (1993), “Stochastic Linear Trends: Models and Estimators," Journal of Econometrics, 56, 5-37.

Mussa, M. (1984), "The Theory of Exchange Rate Determination" in Exchange Rate Theory and Practice, NBER Conference Report, ed. by J. Bilson and R. Marston. Chicago: University of Chicago Press.

Samuelson, P.A. (1964) , "Theoretical notes on trade problems", Review of Economics and Statistics, 46 .

Williamson,J. (ed.) (1994) “Estimating Equilibrium Exchange Rates", Washington, D.C.: Institute for International Economics. 


\section{Appendix}

To derive the asymptotic distribution of $\hat{C}_{\mathrm{e}}$

$$
\hat{C}_{t}=\hat{\alpha}\left(\hat{\beta}^{\prime} \hat{\alpha}\right)^{-1} \hat{\beta}^{\prime} x_{t} .
$$

observe that conditional on $x_{t}$ the only source of variation could arise from $\hat{\alpha}$ and $\hat{\beta}$.

Next notice that a first order expansion of $\hat{C}_{t}$ around $\% \alpha$ and $\beta$ yields

$$
\hat{C}_{t}-C_{t}=C_{t} / \alpha^{\prime}(\hat{\alpha}-\alpha)+C_{t} / \beta^{\prime}(\hat{\beta}-\beta)+O_{p}\left(T^{-1}\right)
$$

and

$$
T^{1 / 2}\left(\hat{C}_{t}-C_{t}\right)=C_{t} / \alpha^{\prime} T^{1 / 2}(\hat{\alpha}-\alpha)+C_{t} / \beta^{\prime} T^{1 / 2}(\hat{\beta}-\beta)+O_{p}\left(T^{-1 / 2}\right) .
$$

Notice also that since $\hat{\beta}$ is $T$ consistent,

$$
T^{1 / 2}(\hat{\beta}-\beta) \stackrel{D}{\rightarrow} 0,
$$

and therefore we can write,

$$
T^{1 / 2}\left(\hat{C}_{t}-C_{t}\right)=C_{\imath} / \alpha^{\prime} T^{1 / 2}(\hat{\alpha}-\alpha)+o_{p}(1)
$$

Thus, all the variation of $\hat{C}_{t}$ arises from $\hat{\alpha}$. Tedious but straightforward matricial algebra yields

$$
C_{t} / \alpha^{\prime}=-C_{t}\left(\beta^{\prime} \alpha\right)^{-1} \beta^{\prime}+\left(\bar{\alpha}^{\prime} C_{t} \otimes I_{N}\right)=Z,
$$

where $\bar{\alpha}=\alpha\left(\alpha^{\prime} \alpha\right)^{-1}, \otimes$ is the Kronecker product and $I_{N}$ is an identity matrix of order $\mathrm{N}$.

We therefore, can write

$$
T^{1 / 2}\left(\hat{C}_{t}-C_{t}\right)=Z T^{1 / 2}(\hat{\alpha}-\alpha)+o_{p}(1)
$$

or

$$
T^{1 / 2}\left(\hat{C}_{t}-C_{t}\right)=Z Z_{\mathbf{1}} T^{1 / 2}(\hat{\Pi}-\Pi)+o_{p}(1),
$$

where $Z_{1}=\left(\bar{\beta}^{\prime} \otimes I_{N}\right)$, with $\bar{\beta}=\beta\left(\beta^{\prime} \beta\right)^{-1}$. The asymptotic distribution of $T^{1 / 2}(\hat{\Pi}-\Pi)$ is known to be Normal with variance $\Sigma_{\pi}$ (see Lutkepohl (1993) for the form of $\Sigma_{\pi}$ ). This implies that $\hat{C}_{t}$ will also be asymptotically normal and therefore,

$$
T^{1 / 2}\left(\hat{C}_{t}-C_{t}\right) \stackrel{a}{\sim} N\left(0, Z Z_{1} \Sigma_{\pi} Z_{1}^{\prime} Z^{\prime}\right)
$$


Table 1: Johansen cointegration tests

\begin{tabular}{|c|c|c|c|c|c|c|c|}
\hline \multicolumn{8}{|c|}{ Stationarity Tests (cv 5.99) q:7.72. NFA:21.4. TNT:34.8. } \\
\hline \multicolumn{8}{|c|}{ Cointegration test, $\operatorname{VAR}(2)$} \\
\hline & $\lambda_{i}$ & Trace-test & $\lambda_{\max }$-test & $5 \% \mathrm{cv} \mathrm{T}$ & $5 \% \mathrm{cr} \lambda$ & $10 \% \mathrm{cv} \mathrm{T}$ & $10 \% \mathrm{cv} \lambda$ \\
\hline$r \leq 2$ & .01 & .47 & .47 & 8.18 & 8.18 & 6.50 & 6.50 \\
\hline$r \leq 1$ & .10 & 10.73 & 9.86 & 17.95 & 14.90 & 15.66 & 12.91 \\
\hline$r=0$ & .20 & $29.67^{*}$ & $19.33^{*}$ & 31.52 & 21.07 & 28.71 & 18.90 \\
\hline \multicolumn{8}{|c|}{$\left({ }^{*}\right)$ Significant at $10 \%$} \\
\hline \multicolumn{8}{|c|}{ Cointegration vector: $q_{t}=.31 N F A_{t}+.42 P_{t}^{N T}$} \\
\hline
\end{tabular}


Figure 1: Real Exchange Rate

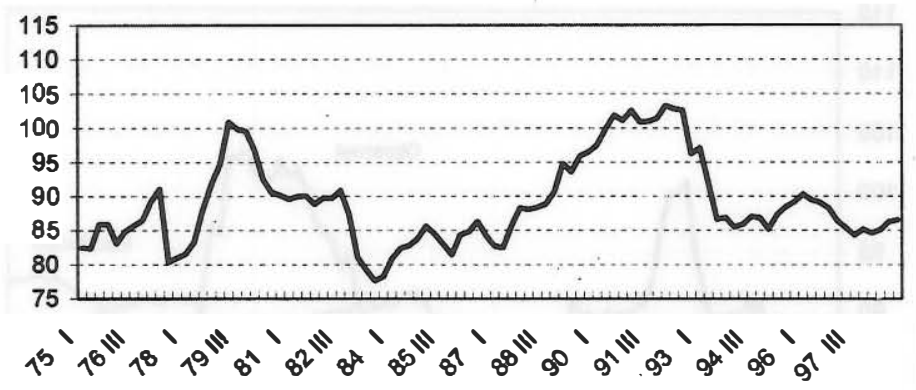

Figure 2: Relative prices

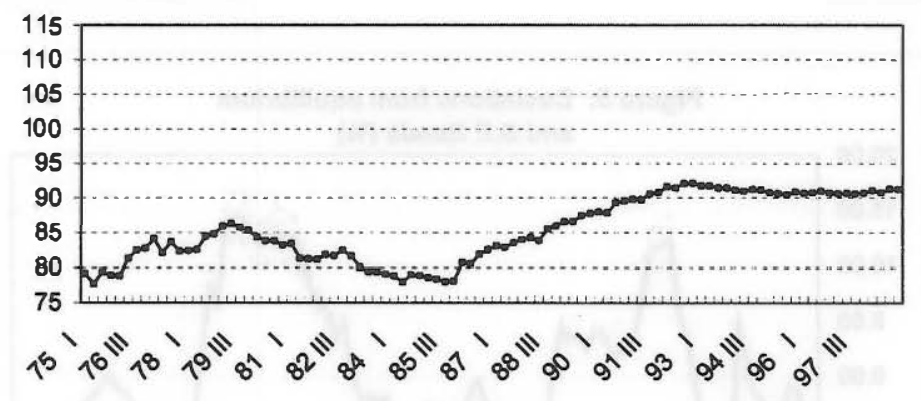

Figure 3: Net Foreign Assets ( \%GDP)

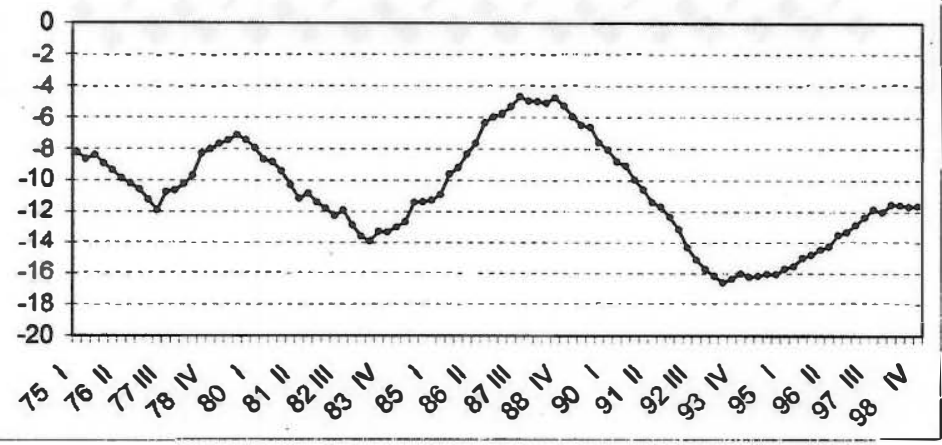

$-29-$ 

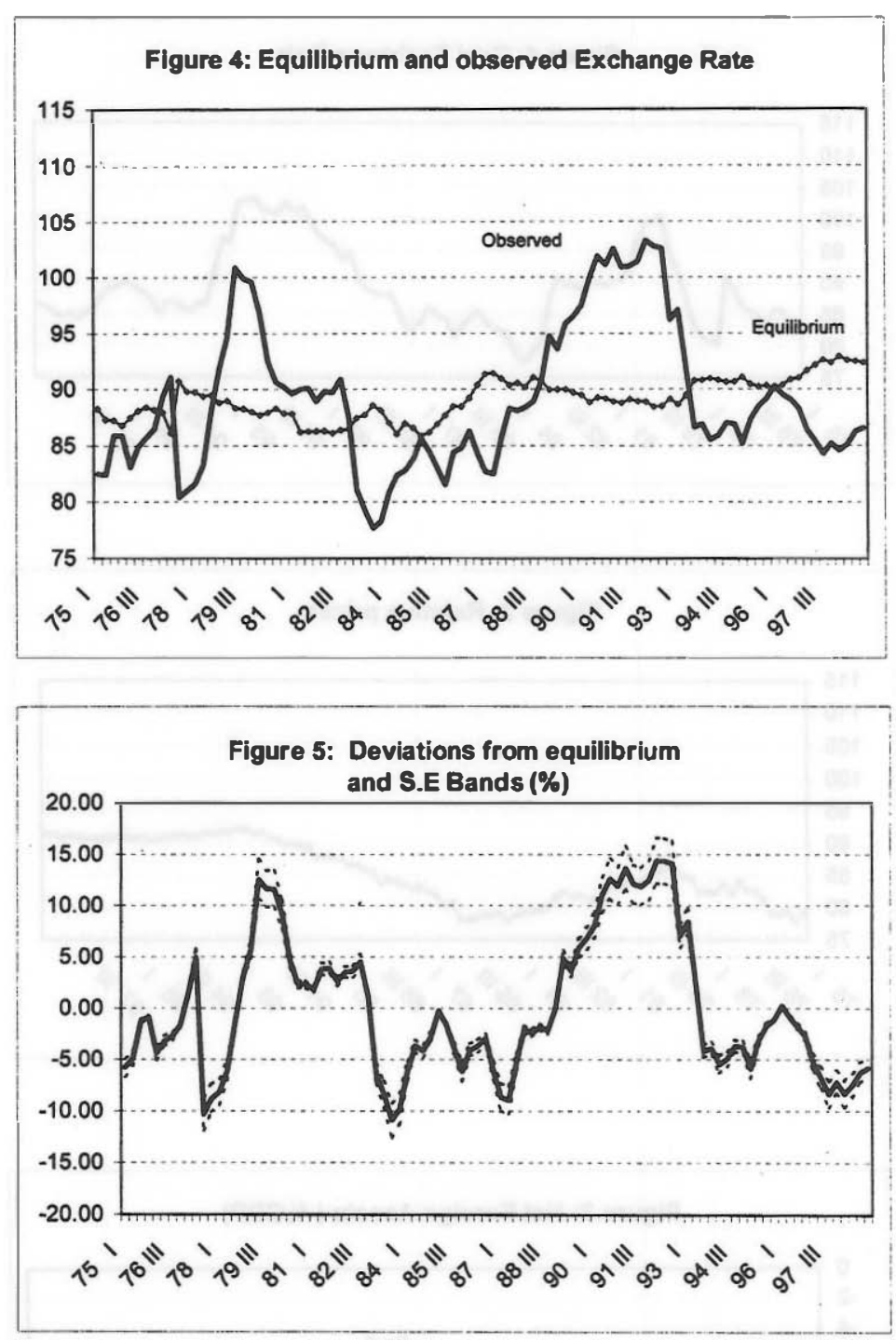


\section{WORKING PAPERS (1)}

9825 Javier Andrés, Ignacio Hernando and J. David López-Salido: The long-run effect of permanent disinflations.

9901 José Ramón Martínez Resano: Instrumentos derivados de los tipos Overnight: call money swaps y futuros sobre fondos federales.

9902 J. Andrés, J. D. Iópez-Salido and J. Vallés: The liquidity effect in a small open economy model.

9903 Olympia Bover and Ramón Gómez: Another look at unemployment duration: long-term unemployment and exit to a permanent job. (The Spanish original of this publication has the same number.)

9904 Ignacio Hemando y Josep A. Tribó: Relación entre contratos laborales y financieros: Un estudio teórico para el caso español.

9905 Cristina Mazón and Soledad Núñez: On the optimality of treasury bond auctions: the Spanish case.

9906 Nadine Watson: Bank Lending Channel Evidence at the Firm Level.

9907 José Vinals: El marco general de la política monetaria única: racionalidad, consecuencias y cuestiones pendientes.

9908 Olympia Bover and Manuel Arellano: Learning about migration decisions from the migrants: an exercise in endogenous samplig and complementary datasets.

9909 Olympia Bover and Pilar Velilla: Migrations in Spain: Historical background and current trends.

9910 Femando Restoy: Los mercados financieros españoles ante la Unión Monetaria.

9911 Luis J. Álvarez and M." de los Llanos Matea: Underlying inflation measures in Spain.

9912 Regina Kaiser and Agustín Maravall: Estimation of the business cycle: a modified HodrickPrescott filter.

9913 Enrique Alberola and José Manuel Marqués: On the relevance and nature of regional inflation differentials: The case of Spain.

9914 Agustin Maravall: An application of TRAMO and SEATS. Report for the «Seasonal Adjustment Research Appraisal» project.

9915 Regina Kaiser and Agustín Maravall: Seasonal outliers in time series.

9916 Enrique Alberola and Humberto I ópez: Internal and external exchange rate equilibrium in a cointegration framework. An application to the Spanish Peseta.

(1) Previously published Working Papers are listed in the Banco de España publications catalogue.

Queries should be addressed to: Banco de España Sección de Publicaciones. Negociado de Distribución y Gestión Telephone: 913385180

Alcalá, 50.28014 Madrid 
